\title{
Erratum to: Existence of mild solutions for fractional nonlocal evolution equations with delay in partially ordered Banach spaces
}

Yue Liang ${ }^{1 *}$, He Yang $^{2}$ and $\mathrm{K} \mathrm{Gou}^{3}$

\section{"Correspondence:}

liangyuegsau@163.com

${ }^{1}$ College of Science, Gansu

Agricultural University, Lanzhou, 730070, P.R. China

Full list of author information is

available at the end of the article
In the publication of this article [1], there was an error in Chapter 4 Application on page 9. The error:

$$
h\left(t, y, x_{t}(\tau, y)\right)\left\{\begin{array} { l l } 
{ 1 , } & { \text { if } x \leq 0 , } \\
{ 1 + 2 x _ { t } ( \tau , y ) , } & { \text { if } 0 < x < 2 , } \\
{ 5 , } & { \text { if } 0 \geq 2 , }
\end{array} \quad g ( x ) ( y ) \left\{\begin{array}{ll}
1, & \text { if } x \leq 0 \\
1+\frac{x(t, y)}{1+x(t, y)}, & \text { if } x>0
\end{array}\right.\right.
$$

Instead should indicate:

$$
h\left(t, y, x_{t}(\tau, y)\right)=\left\{\begin{array}{ll}
1, & \text { if } x \leq 0, \\
1+2 x_{t}(\tau, y), & \text { if } 0<x<2, \\
5, & \text { if } 0 \geq 2,
\end{array} \quad g(x)(y)= \begin{cases}1, & \text { if } x \leq 0 \\
1+\frac{x(t, y)}{1+x(t, y)}, & \text { if } x>0 .\end{cases}\right.
$$

This has now been included in the original article and the erratum.

\section{Author details}

College of Science, Gansu Agricultural University, Lanzhou, 730070, P.R. China. ${ }^{2}$ College of Mathematics and Statistics, Northwest Normal University, Lanzhou, 730070, P.R. China. ${ }^{3}$ Department of Mathematics, Texas A\&M University-Kingsville, Kingsville, 78363, USA.

Received: 2 February 2017 Accepted: 2 February 2017 Published online: 06 February 2017

\section{References}

1. Liang, Y, Yang, H, Guo, K: Existence of mild solutions for fractional nonlocal evolution equations with delay in partially ordered Banach spaces. Bound. Value Probl. 2017, 11 (2017). doi:10.1186/s13662-016-1058-1 (http://creativecommons.org/licenses/by/4.0/), which permits unrestricted use, distribution, and reproduction in any medium, provided you give appropriate credit to the original author(s) and the source, provide a link to the Creative Commons license, and indicate if changes were made. 